iceberg through the water at a speed of 0.5 knots. The two drogues would be pulled alternately, operating, in principle, like the hands of a swimmer doing the Australian crawl. The drag acting on the models was noted to be a fairly strong function of shape and to be least for an "iceberg" whose maximum girth is amidships and whose vertical walls are tapered so that the bow and stern width are approximately $3 / 5$ of the central width. It is envisaged that the next series of tests will involve an actual Arctic iceberg that is roughly $1 / 10$ the size of an Antarctic berg.

A study by D. J. DeMarle (Rochester Institute of Technology, New York) focused on the feasibility of processing icebergs in Saldanha Bay, on the west coast of South Africa. The region has been listed as a future metropolitan growth area by the South African Department of
Environmental Planning. Instead of melting the iceberg on arrival, DeMarle proposed that it be mined using existing technology. A slurry of ice fragments and water would then be pumped ashore via an ocean pipeline. The operation might be powered by the waste heat of a nearby industrial complex, for which a large cold sink could help to increase efficiency.

M. W. Holdgate (Department of the Environment, UK) highlighted the audacious simplicity and social benefits of using icebergs as an inexhaustible source of water. However, such a scheme is not without dangers, not only because of accidents which could result from a stream of broken off icebergs being abandoned in shipping lanes but also because we have little idea of the environmental effects of moving icebergs around the world.

\title{
SRS-A and the leukotrienes
}

\section{from W. Dawson}

THE discovery of a new class of biologically active compounds is always exciting, even at the present time when knowledge is advancing so rapidly.

The leukotrienes are a new structural class deriving from arachidonic acid, a precursor which has already given us the prostaglandins, thromboxanes, prostacyclin and various hydroxy fatty acids. The systems from which the leukotrienes have been released and characterized are closely related to immediate hyper-sensitivity reactions and it has been proposed that SRS-A, slow reacting substance of anaphylaxis is a member of the leukotriene family.

Slow reacting substances (SRS) are socalled because of the characteristic slow contractile response they induce in smooth muscle preparations in vitro. The original SRS from lung tissue was described by Kellaway and Trethewie in 1940, being released from guinea pig lung by snake venom. In a series of papers in the early 1950's Brocklehurst isolated and characterized a similar substance released from guinea pig lung following anaphylactic challenge and named it SRSA. He later jdentified a similar product released in vitro from human lung, derived from an asthmatic person in response to the specific allergen. This work clearly linked SRS-A with the long lasting bronchoconstriction experienced by asthmatics.

W. Dawson is in the Lilly Research Centre Ltd., Windlesham, UK.
For the next 25 years many research groups attempted to identify the chemical structure of SRS-A, notably those of Brocklehurst himself in England and Austen with the late Robert Orange in the USA. Although advances were made, the structure remained elusive. Undoubtedly the extreme potency of SRS-A, the relatively small amounts of material available, and its unusual physicochemical properties were the major causing slow progres of this research.

During the 1960's and early 1970's the prostaglandin (PG) family of structures were identified and their pharmacology described. It seemed natural that the analytical challenge of SRS-A should attract workers in the $P G$ field and within a relatively short period of time publications from many research groups appeared in the literature. The independent work of Parker, Piper and Bach all suggested incorporation of radiolabelled arachidonate into SRS-A-like biological activity whilst two groups, at St. Louis and Lilly, showed incorporation of 35 sulphur. The Harvard group identified sulphur by spark emission spectroscopy in their SRSA preparation and it seemed clear that it was only a matter of time before the structure was revealed.

During 1978 and early 1979, both Parker and Jakschik in St. Louis and Piper and Morris in London suggested various functional groupings which they felt were present in the molecule. In particular, the chromophore at $278-280 \mathrm{~nm}$ seemed a key to the purification of the minute amounts of available SRS, so described because the bulk of the research over this period concentrated on material chemically released with the ionophore $\mathrm{A} 23189$, rather than the immunologically generated SRSA.

In May 1979, at the international prostaglandin conference in Washington, Bengt Samuelsson of the Karakinska Institute in Stockholm, in collaboration with Borgeat, Hammarstrom and Murphy described the work which led to the characterization of the leukotriene (LT) structures LTA, LTB and LTC from a murine mastocytoma cell line and from rabbit polymorpho-nuclear leukocytes. LTA was shown to be 5.6 epoxyarachidonic acid, LTB a dihydroxyarachidonic acid and LTC as 5 hydroxy 6 cysteinyl arachidonic acid. His suggested name derived from the leucocytes which release the material and the conjugated triene system of double bonds in the structure. These double bonds were also responsible for the chromophore at around $280 \mathrm{~nm}$, an observation made by both Piper's and Parker's groups.

A relationship was suggested between this chemically released SRS, now to be known as leukotriene $C$, and SRS-A but the picture was not yet complete. At the end of 1979, and in early 1980 Samuelsson, in collaboration with the chemical group of Corey at Harvard, described LTC as glutathionyl hydroxy arachidonate. Comparison of the biological activities of the natural with totally synthesized material showed them to be identical. It should be stressed, however, that this natural material was chemically released and so could not be correctly called SRS-A. Also, carly in 1980, Piper and Morris characterized an SRS chemically released from guinea pig lung as glycly-cysteinyl hydroxy arachidonate, differing from the LTC described by Corey and Samuelsson by a glutamic acid residue.

In this issue of Nature (p. 104) Piper and Morris describe the first characterization of immunologically released SRS-A from guinea pig lung, achieved with a novel mass spectrometric procedure, and show that it is identical with the chemically released material released from this tissue.

Developments in this field are so rapid, however, that Samuetsson described the same compound at the Winter Prostaglandin Conference in Snowbird, Utah this April and showed that it was formed from leukotriene $C$ by the enzyme A-glutamyltranspeptidase. He named it leukotriene $D$ and described, in collaboration with a number of his colleagues, various aspects of the pharmacology of the leukotriene compounds: $\mathrm{A}, \mathrm{B}, \mathrm{C}$ and $\mathrm{D}$.

It is pertinent to note that the majority of the data presented by the various groups is chemical in nature and the biological activity of these compounds will need to be clearly defined. No doubt in the ensuing months biological flesh will be put on these exciting chemical bones. 